\title{
Vascular endothelial growth inhibitor in human cancer (Review)
}

\author{
NING ZHANG ${ }^{1,2}$, ANDREW J. SANDERS ${ }^{2}$, LIN YE $^{2}$ and WEN G. JIANG ${ }^{2}$ \\ ${ }^{1}$ Department of Urology, Beijing ChaoYang Hospital, Capital University of Medical Science Beijing, 100020 P.R.China; \\ ${ }^{2}$ Metastasis and Angiogenesis Research Group, Cardiff University School of Medicine, Cardiff CF14 4XN, UK
}

Received January 14, 2009; Accepted March 16, 2009

DOI: 10.3892/ijmm_00000198

\begin{abstract}
Vascular endothelial growth inhibitor (VEGI), also known as tumour necrosis factor superfamily member 15 (TNFSF15) and TNF ligand related molecule 1 (TL1), is a recently identified anti-angiogenic cytokine that belongs to the TNF superfamily. Three isoforms of VEGI, VEGI 174, 192, and 251 have been documented, all sharing 151 common $\mathrm{C}$-terminal amino acids but differing in their $\mathrm{N}$-terminal regions. The investigations into the biological functions of VEGI have pointed to a potential cancer inhibitory role for the cytokine. The inhibitory effects of VEGI on cancer are manifested in three main areas, the direct effect on cancer cells, the anti-angiogenic effects on endothelial cells, and stimulation of maturation of dendric cells. The clinical aspect of VEGI in cancer is also being explored in recent years. The present article overviews the recent progress on this molecule and discusses the value of VEGI as a potential therapeutic target in cancer therapy.
\end{abstract}

\section{Contents}

1. Introduction

2. VEGI and TNF superfamily

3. Structure of VEGI and VEGI isoforms

4. Expression and cell/tissue distribution of VEGI

5. Regulation of VEGI expression

6. VEGI and angiogenesis

7. Implication of VEGI in solid tumours

8. Other functions of VEGI involved in carcinoma

9. Perspective

\section{Introduction}

Vascular endothelial growth inhibitor (VEGI) was first reported in 1999 from human umbilical vein endothelial cells $(1,2)$

Correspondence to: Dr Wen G. Jiang, Metastasis and Angiogenesis Research Group, Department of Surgery, Cardiff University School of Medicine, Heath Park, Cardiff CF14 4XN, UK

E-mail: jiangw@cf.ac.uk

Key words: vascular endothelial growth inhibitor, angiogenesis, carcinoma and was found to be identical to another gene known as tumour necrosis factor superfamily member 15 (TNFSF15) and TNF ligand related molecule 1 (TL1). The prime function of VEGI was thought to be anti-angiogenic $(1,2)$. Originally, it was reported to be expressed exclusively in endothelial cells, but more recently VEGI 251 was found to be highly expressed in dendritic cells (DCs) after in vitro activation and in inflammatory bowel disease (IBD), particularly Crohn's disease (CD), rheumatoid arthritis, as well as renal inflammation (3-6). It was believed to be one of the evolutionarily earliest members of the TNF superfamily (7). There is evidence showing that VEGI is involved in atherogenesis. Thus, VEGI is a multipotential cytokine and plays a role in inflammation, septic shock, fever, and growth modulation through the functions of inducing apoptosis, regulating immunity, and anti-angiogenesis.

Moreover, other studies demonstrated an intricate relationship between VEGI and carcinoma in vitro and in vivo (8-11). It is a potent inhibitor of endothelial cell proliferation, angiogenesis, and tumour growth (12). The present review will briefly discuss the VEGI family and focus on the impact of VEGI in cancer.

\section{VEGI and the TNF superfamily}

Three decades ago, lymphotoxin (LT) and tumour necrosis factor- $\alpha$ (TNF) were identified as products of lymphocytes and macrophages that cause lysis of certain types of cells, especially tumour cells $(13,14)$. The two molecules are members of a gene superfamily $(15,16)$. There are at least 19 members so far identified within this family (Table I), which is generally referred to as tumour necrosis factor superfamily (TNFSF). These proteins generally have an intracellular $\mathrm{N}$-terminal domain, a short transmembrane segment, an extracellular stalk, and a globular TNF-like extracellular domain of about 150 residues. These cytokines are either type II transmembrane proteins ( $\mathrm{N}$-terminal inside the cell and C-terminal outside the cell) or soluble proteins (17). TNFSF and TNFSF receptor (TNFSFR) have a diverse array of biological functions, including the growth regulation of normal cells by inducing apoptosis or enhancing cell survival and proliferation. In addition, TNF family members are involved in regulating the immunity, inflammation, bone metabolism, and organogenesis. As a late identified member of the TNF family, VEGI (TNFSF15) shares certain homology in amino acid sequence with other members of the same family, and some of its functions are similar to other members, 
Table I. Members of TNF superfamily.

\begin{tabular}{|c|c|c|c|c|}
\hline TNF family ligands & Human chromosome & Full name & Other names & Reference \\
\hline TNF- $\alpha$ & $6 \mathrm{p} 21.3$ & Tumor Necrosis factor- $\alpha$ & & $(16,35,36)$ \\
\hline TNF- 3 & $6 \mathrm{p} 21.3$ & Tumor Necrosis factor- $\beta$ & Lymphotoxin-a, LTA & $(15,37)$ \\
\hline LTB & $6 \mathrm{p} 21.3$ & Lymphotoxin- $\beta$ & TNFC & $(38)$ \\
\hline $\mathrm{CD} 27 \mathrm{~L}$ & $19 \mathrm{p} 13$ & CD27 antigen ligand & TNFSF7 & (39) \\
\hline CD30L, & 1P36 & CD30 antigen ligand & TNFSF8, Ki-1 & $(40,41)$ \\
\hline CD40L & $\mathrm{Xq} 26$ & CD40 antigen ligand & CD154, TNFSF5,GP39 & $(42)$ \\
\hline FasL & $1 q 23$ & Fas ligand & TNFSF6, CD95L, CD178 & $(43,44)$ \\
\hline 4-1BBL & $19 \mathrm{p} 13.3$ & & TNFSF9 & $(45)$ \\
\hline OX40L (TNFSF4) & $1 q 25$ & OX40 antigen ligand & GP34, TNFSF4, CD134L & (46) \\
\hline TRAIL & $3 q 26$ & $\begin{array}{l}\text { TNF-related apoptosis-inducing } \\
\text { ligand }\end{array}$ & APO2L, TNFSF10 & (47) \\
\hline VEGI(TNFSF15) & $9 q 32$ & Vascular endothelial growth inhibtor & TL1, TNFSF15 & (1) \\
\hline ODF & $13 \mathrm{q} 14$ & Osteoclast differentiation factor & OPGL, RANKL, TRANCE, TNFSF11 & $(48)$ \\
\hline TNFSF13 (APRIL) & & $\begin{array}{c}\text { TNF- and apol-related leukocyte } \\
\text { expressed ligand } 2\end{array}$ & TALL2, TNFSF13 & $(49)$ \\
\hline TNFSF12 & $17 \mathrm{p} 13.3$ & & TWEAK, TWEPRIL,INCLUDED & $(50,51)$ \\
\hline BAFF & $13 q 32-q 34$ & B cell activating factor & TNFSF13B, BLYS, TALL1, THANK & $(52)$ \\
\hline LITAF & 16p13.3-p12 & LPS-induced TNF- $\alpha$ factor & SIMPLE & $(53)$ \\
\hline TNFSF18 & $1 q 23$ & & AITRL, GITRL & $(54,55)$ \\
\hline TNFSF14 & $19 \mathrm{p} 13.3$ & & HVEML & $(56,57)$ \\
\hline C1QTNF5 & $11 \mathrm{q} 23.3$ & $\begin{array}{l}\mathrm{C} 1 \mathrm{q} \text { and tumor necrosis } \\
\text { factor-related protein } 5\end{array}$ & CTRP5 & $(58)$ \\
\hline
\end{tabular}

such as inducing apoptosis of epithelia cells. However, most recent studies indicated potential implications of this molecule in cancer and tumour related angiogenesis.

\section{Structure of VEGI and VEGI isoforms}

In 1997, Tan et al identified a novel TNF-like molecule by searching a cDNA database and named it TL1 (later known as VEGI, TNFSF15 or TL1A) (1). These molecules are abundant in arterial endothelial cells. Hydrophobicity analysis of the protein revealed a 13 amino acid hydrophobic region that follows the amino-terminal segment of 12 residues. VEGI protein has a carboxyl terminus on the exterior cell surface (residues 26-174), a single transmembrane domain, and a short cytoplasmic tail. These features are consistent with characteristics of type II transmembrane proteins.

VEGI protein has $20-30 \%$ sequence identity to other TNF family members, except TNF- $\beta$ (2). The full gene of VEGI is $\sim 17 \mathrm{~kb}$, which consists of four exons and three introns and mapped to human chromosome $9 \mathrm{q} 32$. To date, three splicing variants of VEGI have been reported. The initially reported VEGI protein is composed of 174 amino acids, of which the 1-25 AA residues at the N-terminus are the predicted intracellular and transmembrane domain and the 26-174 residues at the C-terminus form an extracellular domain. The intracellular domain is released after a cleavage (8).

Two other isoforms, VEGI 251 and 192, were discovered subsequently $(10,18,19)$. VEGI 251 is encoded by exons I, II, III $b$ and IV, and VEGI 174 by exons IV and IV b. All three isoforms share a common region of $453 \mathrm{bp}$ that encodes a domain of 24-174 amino acids at the C-terminus of VEGI 174. However, the three isoforms differ in their $\mathrm{N}$-terminal regions due to alternative exons (Fig. 1) (18). In the three isoforms, the longest and most abundant form of VEGI protein contains 251 amino acids and is also known as TL1A (20). Similar to most tumour necrosis factor family members, VEGI 251 is a type II membrane-bound protein with a hydrophobic transmembrane region near the $\mathrm{N}$-terminus and an extracellular carboxyl domain (containing 180 amino acid residues 72-251). Its extracellular domain is cleaved off from the cell membrane by unidentified protease(s) and exists in soluble form (7). The cleavage at different sites generates other soluble forms of VEGI 251 which have different functions, such as VEGI 72251, 101-251, and 106-251. In 2007, Jin et al crystallized recombinant human VEGI 251, which belongs to the tetragonal space group P41212. It has self-rotation functions with three molecules in the asymmetry unit. The three VEGI 251 monomers in the asymmetric unit form a homotrimer that resembles the trimer structure of other TNF ligand family members $(7,20)$. It is now known that only the solubilised extracellular domain of the three isoforms of VEGI is responsible for its biological activity $(8,10,18,19,21)$. For example, full-length VEGI 174 was found to have no effect on tumour growth when over-expressed in cancer cells, whereas a secretable fusion protein (sVEGI) comprising a secretion signal peptide and the putative extracellular domain of VEGI 174 inhibited tumour growth when over-expressed in cancer cells $(9,22,23)$. 


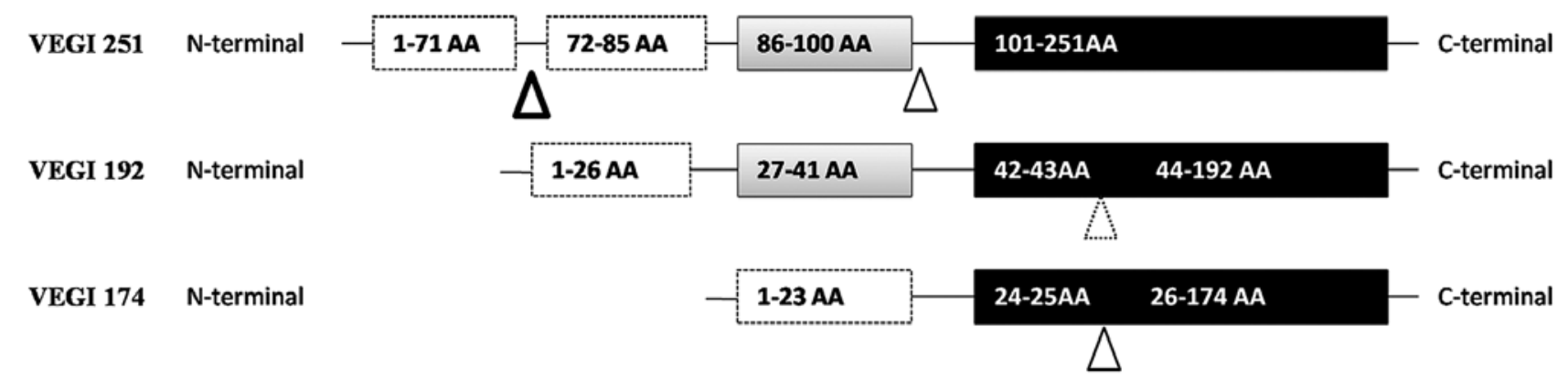

Figure 1. The amino acid structure of the three isoforms of VEGI. VEGI 251, 192, and 174 share a common region of 151 amino acids at the C-terminus (in black boxes). VEGI 251 and 192 share another identical 15 amino acids next to the common region (in gray boxes). However, the three isoforms differ in their N-terminal regions (in blank boxes). The molecular weight of VEGI 251, 192, and 174 is 28,087, 21,857, and 20,131 Da, respectively. In VEGI 251, the extracellular carboxyl domain contains 72-251AA. In VEGI 174, the extracellular carboxyl domain contains 26-174AA. The exact extracellular carboxyl domain of VEGI 192 was not reported previously. In VEGI 251, the cleavage site was in 71 and 72 amino acids. Another cleavage site (XVVR) which was verified in VEGI 174 and 251 also exists in VEGI 192. $\triangle$ Cleavage site.

\section{Expression and cell/tissue distribution of VEGI}

VEGI was originally thought to be exclusively expressed in endothelial cells (24). VEGI 251 and 192 were also detected in the same cell types including HCAE, HUVE, and HMVE cells, but are not seen in HCASM and ABAE. It should also be noted that more than one isoform is expressed in the same cell type, in which VEGI 251 is the most abundant. It is interesting to note that VEGI is highly expressed in some vascularised tissues, such as the kidney but not in other vascularised tissues, such as the heart. This indicates that only a subset of endothelial cells in the tissues expresses VEGI (2). It was found that VEGI is highly expressed in dendritic cells (DCs) after in vitro activation and also up-regulated in Crohn's disease, rheumatoid arthritis, and mouse models of inflammatory bowel disease $(3,25,26)$. Furthermore, VEGI expression was also found in activated lymphocytes, plasma cells, and monocytes $(24,25,27)$.

On the other hand, the tissue distribution of VEGI and its isoforms were also examined. Using Northern blotting, the VEGI transcript was found to be expressed in placenta, lung, kidney, skeletal muscle, pancreas, spleen, prostate, small intestine, and colon. VEGI signal was only rarely detected in heart, brain, liver, thymus, testis, ovary, and peripheral blood lymphocytes (2). VEGI isoforms also have different tissue expression patterns. A $7.5 \mathrm{~kb}$ VEGI 251 transcript was detected in placenta, kidney, lung, and liver, whereas the 2 kb VEGI 174 transcript was observed in liver, kidney, skeletal muscle, and heart. VEGI 251 and 174 were both expressed in prostate, salivary gland, and placenta. However, VEGI 251 is more abundant than VEGI 174 in fetal kidney and lung, whereas VEGI 174 is more abundant in heart, skeletal muscle, pancreas, adrenal gland, and liver (18). VEGI 192 RNA is generally low in tissues and little information is available on this isoform.

\section{Regulation of VEGI expression}

It was reported that TNF- $\alpha$ upregulates the expression of VEGI transcripts in endothelial cells (18). On the other hand, IFN- $\gamma$ showed a suppressive effect on the expression of both basal levels of VEGI, as well as TNF-stimulated VEGI expression.
VEGI utilizes death receptor 3 (DR3, also known as TNFRSF25) for its biological functions. VEGI activation results in activation of nuclear factor $-\kappa \mathrm{B}(\mathrm{NF}-\kappa \mathrm{B})$, a central transcription factor that controls expression of numerous genes in the immune system. Recombinant soluble VEGI induces $\mathrm{NF}-\kappa \mathrm{B}$ activation in DR3-expressing cells and increases ectopic expression of VEGI in human endothelial cells (18). This suggests VEGI regulates its own expression in an autocrine manner. In a mouse model, it was found that a full-length mouse VEGI gene is transcribed from a major transcription initiation site. Critical control of VEGI expression resides in a segment within the promoter that carries NF- $\mathrm{KB}$ and specificity protein-1 (SP1) binding sites, and binding of NF- $\mathrm{KB}$ to this site is important for basal and TNF- $\alpha$ induced VEGI expression (22).

\section{VEGI and angiogenesis}

Angiogenesis is essential for many physiological (as seen in uterus and in wound healing) and pathological (such as cancer, rheumatoid arthritis and diabetes) processes $(28,29)$. The process of angiogenesis involves cell proliferation, migration, tubule formation of endothelial cells, remodelling of the extracellular matrix, and invasion to surrounding tissue (30), and is tightly regulated by a balance of pro- and anti-angiogenic molecules $(9,30)$. A number of endogenous angiogenesis inhibitors, such as angiostatin, endostatin, restin, canstatin, and tumstatin were reported and have been shown to suppress the growth of primary and metastatic tumours without affecting the normal vasculature (31).

VEGI induces apoptosis in endothelial cells via an autocrine pathway $(2,18,32)$. Its mRNA was also found in many normal and tumour tissues, and tumour cell lines, suggesting a physiological and pathological role for this unique molecule in the regulation of new vasculature. Over-expression of VEGI was shown to inhibit tumour neovascularisation and progression in cellular and animal models $(8,32)$.

Using recombinant VEGI protein consisting of the putative extracellular domain of VEGI, it was found that the protein inhibited the growth of capillary-like structures regardless of the cause of the angiogenic process in vitro and markedly inhibits the growth of breast cancer and colon cancer xenograft 
tumours $(2,8)$. The antitumour effect of VEGI is likely to result from the ability of VEGI to suppress neovascularisation because recombinant VEGI has no inhibitory activity on the growth of cancer cells in vitro. Furthermore, over-expression of VEGI 251 induced apoptosis in endothelial cells (18) and inhibited the growth of xenograft tumours and corresponding microvessel density (18). However, over-expression of fulllength VEGI 174 by cancer cells has little effect on the growth of the xenograft tumours. Further investigation has shown that the density of endothelial cells exhibited an $88 \%$ decrease within 1 week of treatment with recombinant human VEGI 192 and a further decrease within 3 weeks (10). Interestingly, the number of the smooth muscle cells remained relatively unchanged. However, it was unclear whether the residual vascular structures would supply enough blood circulation in the tumours. Nonetheless, additional evidence indicates that the antitumour activity of sVEGI is not due to a direct effect on tumour cells but rather to an interference with the development of tumour-associated vasculature $(22,28)$.

A few mechanisms underlying the inhibitory effect of VEGI on endothelial cells were revealed. First, VEGI prevents G0/G1 cells from re-entering the cell cycle in response to growth stimuli. Second, there are two members of the TNF receptor superfamily which VEGI interacts with, namely death receptor 3 (DR3) and decoy receptor 3 (DcR3). DR3 is the functional receptor of VEGI 251. It contains a death domain in its cytoplasmic tail and induces apoptosis in death receptor-3-expressing cell lines, such as in human umbilical vein endothelial cells (HUVECs). On the contrary, previous studies indicated that DcR3 is over-expressed in malignant tumours arising from oesophagus, stomach, glioma, lung, colon, and rectum $(20,22,25-27)$. DcR3 enhances angiogenesis by blocking the autocrine angiostatic function of VEGI in human umbilical vein endothelial (27). Meanwhile, anti-VEGI and -DR3 antibodies lead to increases of both cell proliferation and motility, and an induction of the formation of tube network (28). The angiogenic effect of VEGI antibody and DR3 antibody is similar to that induced by DcR3. Furthermore, VEGI induces apoptosis in actively proliferating cells, via activation of the stress protein kinases, SAPK/JNK and p38 MAPK (SAPK, stress-activated protein kinase, JNK, c-Jun N-terminal protein kinase, p38 MAPK, p38 mitogenactivated protein kinase), and the caspases, mainly caspase-3like protease. Additionally, VEGI-induced apoptosis is attenuated by the caspase inhibitor.

In contrast, no obvious inhibitory effect on proliferation of the blood vessels of chorioallantoic membrane was seen after treatment with VEGI 72-251 in another study (19). The authors suggested that although the 151 residues at the C-terminal of VEGI 72-251 is identical with that of VEGI 24-174, the assay of biological activity found that VEGI 72-251 did not possess the biological activities of VEGI 24-174, such as inhibiting the growth of endothelial cells. The results indicated that soluble VEGI 72-251 is not able to bind with endothelial cells, which is due to a change of protein structure. Another investigation reported that truncated VEGI 251 proteins, which correspond to amino acids 101-251 and 106-251 of VEGI 251, both have an antiangiogenic effect (24).

The C-terminus 151 amino acids from all known forms of VEGI are the same and this part of the protein, when expressed alone, induced apoptosis of endothelial cells within $36 \mathrm{~h}$. Overexpression of the full-length VEGI did not give rise to a VEGI peptide in cell conditioned media and did not show antiangiogenic activity in vivo. This suggests the soluble domain of VEGI is critical for this negative regulator of angiogenesis produced predominantly by endothelial cells, but not when it is associated with the amino-terminal cytoplasmic and transmembrane domains of VEGI (residues 1-23). Endothelial cellsecreted VEGI functions as an autocrine inhibitor of angiogenesis and a naturally existing modulator of vascular homeostasis. Thus, this novel gene is not only vital for future study of vascular biology but also is a potential target in the development of angiogenesis-based cancer therapy.

\section{Implication of VEGI in solid tumours}

The expression and effect of VEGI were investigated in a wide variety of human cancer cell lines, including breast, prostate, bladder, colorectal and liver, and also expressed in human epithelial cells (9). Moreover, recent studies revealed a profound implication of VEGI in clinical cancer.

VEGI is able to inhibit the growth of various human tumour cell lines including human histiocytic lymphoma (U-937), human breast carcinoma (MCF-7), human epithelial carcinoma (HeLa) and human myeloid lymphoma ML-1a (11). VEGI was also shown to inhibit tumour growth in vivo. VEGI also suppresses the growth of colon carcinoma cells (murine colon cancer cells, MC-38) both in vitro and in vivo $(2,8,22)$. Systemic administration of VEGI 192 remarkably inhibited tumour growth and increased survival time of the treated animals in a Lewis lung cancer (LLC) murine tumour model. As much as $50 \%$ inhibition of the tumour growth rate was achieved with treatment from which no obvious liver and kidney toxicity was found (10). In 2006, Parr et al reported that patients with breast tumours expressing reduced levels of VEGI had a higher local recurrence, shorter survival time and an overall poorer prognosis than those patients expressing high levels of VEGI. In addition, VEGI levels tended to be lower in lobular tumours compared to tumours of ductal origin. However, no significant correlations were observed between VEGI expression and tumour grade, TNM classification, or nodal involvement (9). It is plausible that the pro-apoptotic effect of soluble VEGI in endothelial cells is critical for its anti-tumour activity $(10,19-22,28,32,33)$. However, it is unclear whether other mechanisms, such as activation of tumourspecific or non-specific B or T lymphocytes or induction of cytokines (18), also operate in the soluble VEGI-mediated tumour suppression.

\section{Other functions of VEGI involved in carcinoma}

VEGI is a $\mathrm{T}$ cell costimulator. It directly stimulates DC maturation, and induces nuclear factor- $\kappa \mathrm{B}$ activation and apoptosis in death receptor-3-expressing cell lines. However, it is unclear whether these mechanisms are involved in the VEGI-mediated tumour suppression.

The structure of VEGI itself is of interest when considering its functions. While VEGI 24-174 is anti-angiogenic, VEGI 72251 serves as an anti-cancer factor through its activation of T lymphocytes (19,20). VEGI 72-251, not VEGI 24-174, binds 
$\mathrm{T}$ cell receptors. The functional receptor for VEGI 251 is DR3 (6), which is predominantly expressed on activated lymphocytes. Ligand-receptor binding creates co-stimulatory signals for $\mathrm{T}$ cells, increases IL-2 responsiveness and secretion of IFN- $\gamma$ and GM-CSF, both in vitro and in vivo. There are suggestions that the anti-cancer activities of VEGI 72-251 mainly depend on the stimulation of $\mathrm{T}$ cells but not on antiangiogenesis $(19,20,24)$. Moreover, VEGI 251 binds to DR3 and activates $\mathrm{NF}-\mathrm{\kappa B}$, caspase, induces c-IAP2 production and regulates DR3 mediated apoptosis in the tumour cell line TF-1 $(20,24,34)$. However, this interaction fails to induce significant caspase activation or apoptosis in T cells. These results suggest that VEGI 251 and DR3 are involved in multiple diseases where immunity plays a major role. VEGI 251 mediates cancer rejection through tumour-specific or nonspecific B or T lymphocytes or induction of cytokines. However, these functions are inhibited in the presence of a decoy receptor (DcR3, also known as TR6, or TNFRSF21), which competes for the binding of VEGI $251(20,24,34)$. Upon binding to DR3, VEGI 251 directly stimulates DC maturation, which is an essential component of host immunity against cancer development (33). Collectively, it suggests that VEGI 251 plays a central role in the interaction between the endothelium and the immune system to modulate angiogenesis and inflammation toward the suppression of tumour development and progression.

\section{Perspective}

Further investigation of VEGI and the signal pathways will expand the understanding of its role in cancer and tumour related angiogenesis. For example, the exact membrane receptor responsible for VEGI induced endothelial cell apoptosis is yet to be clarified. Second, underlying mechanisms, such as activation of tumour- or non-specific B or T lymphocytes or induction of cytokines and soluble VEGI-mediated tumour rejection are yet to be established (2). Third, the upregulation of VEGI transcripts by TNF- $\alpha$ indicates that VEGImediated activity is potentially a target of TNF- $\alpha$ action. Fourth, the clinical impact of circulating VEGI in cancer should be studied in detail. It was reported that VEGI is not only expressed in HUVECs but also secreted to the culture medium (28). In certain inflammatory diseases, VEGI also has a remarkable increase in peripheral blood. Little is known about the serum level of VEGI in cancer. Synthetic chimeric protein VEGI-CTT was demonstrated to be an effective inhibitor of lymphoma tumour growth in vivo, and it has a more potent antitumour activity than VEGI, CTT, or the combination of both (28). Further investigation will highlight the regulation of VEGI functions by other anti-angiogenesis or -cancer factors.

VEGI serves as a potential target in the development of angiogenesis-based cancer therapy. In contrast to the function of DR3, a soluble DcR3 is generated to interfere with the autocrine function of VEGI (28). Increasing expression of DcR3 was indicated in various solid tumours, which protects vascular endothelial cells from induced apoptosis by VEGI and contributes to tumour related angiogenesis. Targeting at DcR3 has provided a potential approach to block tumour associated angiogenesis.
In summary, the aberrance of VEGI expression and function was implicated in carcinoma and related angiogenesis. Future study will elucidate mechanisms of VEGI regulation and its role in angiogenesis under both physiological and pathological conditions. It will also provide novel therapeutic approaches for targeting carcinoma and angiogenesis.

\section{Acknowledgements}

The authors would like to thank the Albert Hung Foundation and Cancer Research Wales for their support. Dr N. Zhang is a recipient of the China Medical Scholarship of Cardiff University.

\section{References}

1. Tan KB, Harrop J, Reddy M, et al: Characterization of a novel TNF-like ligand and recently described TNF ligand and TNF receptor superfamily genes and their constitutive and inducible expression in hematopoietic and non-hematopoietic cells. Gene 204: 35-46, 1997.

2. Zhai Y, Ni J, Jiang GW, et al: VEGI, a novel cytokine of the tumor necrosis factor family, is an angiogenesis inhibitor that suppresses the growth of colon carcinomas in vivo. FASEB J 13: 181-189, 1999.

3. Bamias G, Martin C 3rd, Marini M, et al: Expression, localization, and functional activity of TL1A, a novel Th1polarizing cytokine in inflammatory bowel disease. J Immunol 171: 4868-4874, 2003.

4. Prehn JL, Mehdizadeh S, Landers CJ, et al: Potential role for TL1A, the new TNF-family member and potent costimulator of IFN-gamma, in mucosal inflammation. Clin Immunol 112: 66-77, 2004.

5. Al-Lamki RS, Wang J, Tolkovsky AM, et al: TL1A both promotes and protects from renal inflammation and injury. $J$ Am Soc Nephrol 19: 953-960, 2008.

6. Bamias G, Siakavellas SI, Stamatelopoulos KS, Chryssochoou E, Papamichael C and Sfikakis PP: Circulating levels of TNF-like cytokine $1 \mathrm{~A}$ (TL1A) and its decoy receptor 3 (DcR3) in rheumatoid arthritis. Clin Immunol 129: 249-255, 2008.

7. Jin T, Guo F, Kim S, Howard A and Zhang YZ: X-ray crystal structure of TNF ligand family member TL1A at 2.1A. Biochem Biophys Res Commun 364: 1-6, 2007

8. Zhai Y, Yu J, Iruela-Arispe L, et al: Inhibition of angiogenesis and breast cancer xenograft tumor growth by VEGI, a novel cytokine of the TNF superfamily. Int J Cancer 82: 131-136, 1999.

9. Parr C, Gan CH, Watkins G and Jiang WG: Reduced vascular endothelial growth inhibitor (VEGI) expression is associated with poor prognosis in breast cancer patients. Angiogenesis 9: 73-81, 2006.

10. Hou W, Medynski D, Wu S, Lin X and Li LY: VEGI-192, a new isoform of TNFSF15, specifically eliminates tumor vascular endothelial cells and suppresses tumor growth. Clin Cancer Res 11: 5595-5602, 2005.

11. Haridas V, Shrivastava A, Su J, et al: VEGI, a new member of the TNF family activates nuclear factor-kappa B and c-Jun Nterminal kinase and modulates cell growth. Oncogene 18: 6496-6504, 1999.

12. Yu J, Tian S, Metheny-Barlow L, et al: Modulation of endothelial cell growth arrest and apoptosis by vascular endothelial growth inhibitor. Circ Res 89: 1161-1167, 2001.

13. Granger GA, Shacks SJ, Williams TW and Kolb WP: Lymphocyte in vitro cytotoxicity: specific release of lymphotoxin-like materials from tuberculin-sensitive lymphoid cells. Nature 221: 1155-1157, 1969

14. Carswell EA, Old LJ, Kassel RL, Green S, Fiore N and Williamson B: An endotoxin-induced serum factor that causes necrosis of tumors. Proc Natl Acad Sci USA 72: 3666-3670, 1975.

15. Gray PW, Aggarwal BB, Benton CV, et al: Cloning and expression of cDNA for human lymphotoxin, a lymphokine with tumour necrosis activity. Nature 312: 721-724, 1984.

16. Pennica D, Nedwin GE, Hayflick JS, et al: Human tumour necrosis factor: precursor structure, expression and homology to lymphotoxin. Nature 312: 724-729, 1984. 
17. Younes A and Kadin ME: Emerging applications of the tumor necrosis factor family of ligands and receptors in cancer therapy. J Clin Oncol 21: 3526-3534, 2003.

18. Chew LJ, Pan H, Yu J, et al: A novel secreted splice variant of vascular endothelial cell growth inhibitor. FASEB J 16: 742-744, 2002.

19. Yao JJ, Zhang M, Miao XH, et al: Isoform of vascular endothelial cell growth inhibitor (VEGI72-251) increases interleukin-2 production by activation of $\mathrm{T}$ lymphocytes. Acta Biochim Biophys Sin (Shanghai) 38: 249-253, 2006.

20. Jin T, Kim S, Guo F, Howard A and Zhang YZ: Purification and crystallization of recombinant human TNF-like ligand TL1A. Cytokine 40: 115-122, 2007.

21. Park SS, Lillehoj HS, Hong YH and Lee SH: Functional characterization of tumor necrosis factor superfamily 15 (TNFSF15) induced by lipopolysaccharides and Eimeria infection. Dev Comp Immunol 31: 934-944, 2007.

22. Xiao Q, Hsu CY, Chen H, Ma X, Xu J and Lee JM: Characterization of cis-regulatory elements of the vascular endothelial growth inhibitor gene promoter. Biochem J 388: 913-920, 2005.

23. Kim S and Zhang L: Identification of naturally secreted soluble form of TL1A, a TNF-like cytokine. J Immunol Methods 298: $1-8,2005$

24. Migone TS, Zhang J, Luo X, et al: TL1A is a TNF-like ligand for DR3 and TR6/DcR3 and functions as a T cell costimulator. Immunity 16: 479-492, 2002.

25. Bamias G, Mishina M, Nyce M, et al: Role of TL1A and its receptor DR3 in two models of chronic murine ileitis. Proc Nat Acad Sci USA 103: 8441-8446, 2006.

26. Cassatella MA, Pereira-da-Silva G, Tinazzi I, et al: Soluble TNF-like cytokine (TL1A) production by immune complexes stimulated monocytes in rheumatoid arthritis. J Immunol 178 7325-7333, 2007.

27. Prehn JL, Thomas LS, Landers CJ, Yu QT, Michelsen KS and Targan SR: The T cell costimulator TL1A is induced by FcgammaR signaling in human monocytes and dendritic cells. J Immunol 178: 4033-4038, 2007.

28. Yang CR, Hsieh SL, Teng CM, Ho FM, Su WL and Lin WW: Soluble decoy receptor 3 induces angiogenesis by neutralization of TL1A, a cytokine belonging to tumor necrosis factor superfamily and exhibiting angiostatic action. Cancer Res 64: 1122-1129, 2004.

29. Conway KP, Price P, Harding KG and Jiang WG: The role of vascular endothelial growth inhibitor in wound healing. Int Wound J 4: 55-64, 2007

30. Carmeliet P: Mechanisms of angiogenesis and arteriogenesis. Nat Med 6: 389-395, 2000.

31. Cai J, Wei R and Cheng J: Preparation and characterization of a novel chimeric protein VEGI-CTT in Escherichia coli. J Biomed Biotechnol 2008: 564969, 2008.

32. Yue TL, Ni J, Romanic AM, et al: TL1, a novel tumor necrosis factor-like cytokine, induces apoptosis in endothelial cells Involvement of activation of stress protein kinases (stress-activated protein kinase and p38 mitogen-activated protein kinase) and caspase-3-like protease. J Biol Chem 274: 1479-1486, 1999.

33. Tian F, Grimaldo S, Fujita M, Cutts J, Vujanovic NL and Li LY: The endothelial cell-produced antiangiogenic cytokine vascular endothelial growth inhibitor induces dendritic cell maturation. J Immunol 179: 3742-3751, 2007.

34. Papadakis KA, Prehn JL, Landers C, et al: TL1A synergizes with IL-12 and IL-18 to enhance IFN-gamma production in human T cells and NK cells. J Immunol 172: 7002-7007, 2004.

35. Wang AM, Creasey AA, Ladner MB, et al: Molecular cloning of the complementary DNA for human tumor necrosis factor. Science 228: 149-154, 1985

36. Shirai $\mathrm{T}$, Yamaguchi $\mathrm{H}$, Ito $\mathrm{H}$, Todd $\mathrm{CW}$ and Wallace RB: Cloning and expression in Escherichia coli of the gene for human tumour necrosis factor. Nature 313: 803-806, 1985.

37. Aggarwal BB, Eessalu TE and Hass PE: Characterization of receptors for human tumour necrosis factor and their regulation by gamma-interferon. Nature 318: 665-667, 1985.
38. Browning JL, Ngam-ek A, Lawton $\mathrm{P}$, et al: Lymphotoxin beta, a novel member of the TNF family that forms a heteromeric complex with lymphotoxin on the cell surface. Cell 72: 847-856, 1993.

39. Goodwin RG, Alderson MR, Smith CA, et al: Molecular and biological characterization of a ligand for CD27 defines a new family of cytokines with homology to tumor necrosis factor. Cell 73: 447-456, 1993.

40. Stein H, Gerdes J, Schwab U, et al: Identification of Hodgkin and Sternberg-reed cells as a unique cell type derived from a newlydetected small-cell population. Int J Cancer 30: 445-459, 1982.

41. Durkop H, Latza U, Hummel M, Eitelbach F, Seed B and Stein H: Molecular cloning and expression of a new member of the nerve growth factor receptor family that is characteristic for Hodgkin's disease. Cell 68: 421-427, 1992.

42. Gauchat JF, Aubry JP, Mazzei G, et al: Human CD40-ligand: molecular cloning, cellular distribution and regulation of expression by factors controlling IgE production. FEBS Lett 315: 259-266, 1993.

43. Takahashi T, Tanaka M, Brannan CI, et al: Generalized lymphoproliferative disease in mice, caused by a point mutation in the Fas ligand. Cell 76: 969-976, 1994.

44. Takahashi T, Tanaka M, Inazawa J, Abe T, Suda T and Nagata S: Human Fas ligand: gene structure, chromosomal location and species specificity. Int Immunol 6: 1567-1574, 1994.

45. Alderson MR, Smith CA, Tough TW, et al: Molecular and biological characterization of human 4-1BB and its ligand. Eur J Immunol 24: 2219-2227, 1994.

46. Miura S, Ohtani K, Numata N, et al: Molecular cloning and characterization of a novel glycoprotein, gp34, that is specifically induced by the human T-cell leukemia virus type I transactivator p40tax. Mol Cell Biol 11: 1313-1325, 1991.

47. Wiley SR, Schooley K, Smolak PJ, et al: Identification and characterization of a new member of the TNF family that induces apoptosis. Immunity 3: 673-682, 1995.

48. Lacey DL, Timms E, Tan HL, et al: Osteoprotegerin ligand is a cytokine that regulates osteoclast differentiation and activation. Cell 93: 165-176, 1998.

49. Hahne M, Kataoka T, Schroter M, et al: APRIL, a new ligand of the tumor necrosis factor family, stimulates tumor cell growth. J Exp Med 188: 1185-1190, 1998 .

50. Chicheportiche Y, Bourdon PR, Xu H, et al: TWEAK, a new secreted ligand in the tumor necrosis factor family that weakly induces apoptosis. J Biol Chem 272: 32401-32410, 1997.

51. Pradet-Balade B, Medema JP, Lopez-Fraga M, et al: An endogenous hybrid mRNA encodes TWE-PRIL, a functional cell surface TWEAK-APRIL fusion protein. EMBO J 21: 5711-5720, 2002.

52. Moore PA, Belvedere O, Orr A, et al: BLyS: member of the tumor necrosis factor family and B lymphocyte stimulator. Science 285: 260-263, 1999

53. Takashiba S, Van Dyke TE, Shapira L and Amar S: Lipopolysaccharide-inducible and salicylate-sensitive nuclear factor(s) on human tumor necrosis factor alpha promoter. Infect Immun 63: 1529-1534, 1995.

54. Kwon B, Yu KY, Ni J, et al: Identification of a novel activationinducible protein of the tumor necrosis factor receptor superfamily and its ligand. J Biol Chem 274: 6056-6061, 1999.

55. Nocentini G, Giunchi L, Ronchetti S, et al: A new member of the tumor necrosis factor/nerve growth factor receptor family inhibits T cell receptor-induced apoptosis. Proc Natl Acad Sci USA 94: 6216-6221, 1997.

56. Mauri DN, Ebner R, Montgomery RI, et al: LIGHT, a new member of the TNF superfamily, and lymphotoxin alpha are ligands for herpesvirus entry mediator. Immunity 8: 21-30, 1998.

57. Harrop JA, McDonnell PC, Brigham-Burke M, et al: Herpesvirus entry mediator ligand (HVEM-L), a novel ligand for HVEM/TR2, stimulates proliferation of $\mathrm{T}$ cells and inhibits HT29 cell growth. J Biol Chem 273: 27548-27556, 1998.

58. Agarwal N, Swaroop A, Zheng K, et al: Expression and chromosomal localization of cDNA clones from an enriched human retinal pigment epithelial (RPE) cell line library: identification of two RPE-specific genes. Cytogenet Cell Genet 69: $71-74,1995$. 